Revue

Revue de l'histoire des religions

del'histoire des religions

$4 \mid 2006$

Varia

\title{
Antoine Guillaumont, Un philosophe au désert, Évagre le Pontique
}

Paris, J. Vrin, 2004, (« Textes et traditions », 8)

Florence Jullien

\section{(2) OpenEdition}

Journals

Édition électronique

URL : http://journals.openedition.org/rhr/5217

DOI : $10.4000 /$ rhr. 5217

ISSN : 2105-2573

Éditeur

Armand Colin

Édition imprimée

Date de publication : 1 décembre 2006

Pagination : 492-496

ISBN : 978-2-2009-2106-4

ISSN : 0035-1423

Référence électronique

Florence Jullien, « Antoine Guillaumont, Un philosophe au désert, Évagre le Pontique », Revue de l'histoire des religions [En ligne], 4 | 2006, mis en ligne le 28 janvier 2010, consulté le 22 septembre 2020. URL: http://journals.openedition.org/rhr/5217 ; DOI : https://doi.org/10.4000/rhr.5217

Ce document a été généré automatiquement le 22 septembre 2020.

Tous droits réservés 


\section{Antoine Guillaumont, Un philosophe au désert, Évagre le Pontique}

Paris, J. Vrin, 2004, (« Textes et traditions », 8)

Florence Jullien

\section{RÉFÉRENCE}

Antoine Guillaumont, Un philosophe au désert, Évagre le Pontique, Paris, J. Vrin, 2004, 430 p. («Textes et traditions », 8).

1 A. G. nous livre le couronnement de ses recherches sur Évagre, dont il reste le spécialiste incontesté. Cet ouvrage posthume, huitième de la collection «Textes et traditions " éditée chez J. Vrin, offre une véritable synthèse des connaissances sur l'œuvre, la pensée et la biographie d'un des plus illustres et influents penseurs de la vie monastique du IV e s., Évagre. Originaire d'Ibora dans le Pont, en Asie mineure, il naquit vers 345. Son père était chorévêque, chargé d'administrer pour l'évêque du lieu les églises des campagnes. Si Basile de Césarée dut avoir une influence certaine sur sa formation intellectuelle, c'est Grégoire de Nazianze qu'Évagre présente comme son maître auprès duquel il séjourna, à Constantinople, dès 379 , suite à la mort de Basile. Une aventure sentimentale le contraignit à quitter la capitale byzantine ; Évagre se fixa alors en Palestine auprès de Rufin et de Mélanie, lecteurs d'Origène, qui avaient respectivement fondé un monastère pour l'accueil des pèlerins. À leur contact, il décida d'embrasser la vie monastique, et partit pour Nitrie en Égypte vers la fin de 383. Il gagna le désert des Kellia (des "cellules») où, durant quatorze années, il vécut en ermitage, retrouvant les frères en fin de semaine pour la synaxe, liturgie célébrée à l'église et suivie du repas communautaire. A. G. souligne que la venue d'Évagre aux Kellia en 385 correspondait à l'époque la plus florissante des déserts de Basse-Égypte (p. 53) : la mémoire des plus grands ascètes comme Antoine était toujours vive; Macaire "l'Égyptien", disciple d'Antoine, n'était pas encore mort et exercera d'ailleurs une profonde influence sur lui. Des frères se groupèrent bientôt, proches 
intellectuellement, entretenant parfois pour certains d'entre eux, comme Ammonios, des liens avec Rufin de Palestine. L'autorité d'Évagre se renforça peu à peu grâce à son enseignement fondé surtout sur l'exégèse allégorique des textes scripturaires, à la manière d'Origène (p. 59). Il mourut probablement au cours de l'année 399, et ne connut donc pas la crise qui se déchaîna aux Kellia, à l'instigation de l'évêque Théophile d'Alexandrie, opposant les "anthropomorphites ", nombreux à Scété, aux origénistes majoritaires aux Kellia ; Ammonios et de nombreux frères s'exilèrent alors en Palestine.

Dans le IV $\mathrm{IV}^{\mathrm{e}}$ chapitre de cette première partie consacrée à la vie d'Évagre, l'A. présente son expérience monastique, via quelques passages significatifs de ses écrits, principalement l'Antirrhétique - analyse des tentations auxquelles doit faire face le moine et où affleure son expérience personnelle (p. 65-75). Le dernier chapitre analyse «le jugement de la postérité » sur Évagre au lendemain de sa mort : son appartenance au groupe des moines qui, aux Kellia, furent poursuivis comme origénistes, devait affecter sa mémoire. Ainsi la sévère appréciation de Jérôme finit par influencer tout l'Occident latin; cependant, par Cassien, profondément marqué par la doctrine évagrienne, «la doctrine ascétique d'Évagre fournit des éléments fondamentaux à la tradition monastique et à la spiritualité de l'Occident » (p. 78 et n. 1).

Pallade, futur évêque d'Hélénopolis en Bithynie, venu aux Kellia en 390, fut son disciple et son biographe: son Histoire lausiaque, rédigée vers 420, comporte un chapitre consacré au maître - la principale source dont nous disposons pour connaître sa vie. Il existe plusieurs versions de cette Histoire, en latin, en copte mais aussi en syriaque (ms. $\mathrm{du} \mathrm{VI}^{\mathrm{e}} \mathrm{s}$., alors que le plus ancien ms. grec remonte au X ${ }^{\mathrm{e}} \mathrm{s}$.) et en arménien. Au VII ${ }^{\mathrm{e}}$ s., un moine de Beth-Abé', 'Enanisho', intégra l'une de ces recensions syriaques dans le Livre $d u$ Paradis, compilation de textes monastiques d'origine égyptienne. Parmi les autres sources sont mentionnées: la Relation sur les moines d'Égypte, en grec, dont Rufin d'Aquilée, ami d'Évagre, fit une traduction latine, y ajoutant d'autres détails; l'Histoire ecclésiastique de Socrate (Livre IV) et celle de Sozomène (Livre VI), du V $\mathrm{V}^{\mathrm{e}}$ s. ; la collection des Apophtegmata Patrum ( $\mathrm{V}^{\mathrm{e}} \mathrm{s}$.) ; enfin la correspondance d'Évagre lui-même et ses propres écrits.

Les ouvrages d'Évagre connurent un réel rayonnement du vivant même de leur auteur ; ils étaient lus dans les monastères du Sinaï et de Palestine. Mais l'hostilité de certains couvents, comme la laure de saint Sabas, suscita une condamnation de la doctrine d'Origène et d'Évagre lors du $\mathrm{V}^{\mathrm{e}}$ concile œcuménique de Constantinople en 553 : cette condamnation officielle devait jeter un discrédit durable sur l'œuvre d'Évagre, ce qui explique aussi la difficulté de sa transmission en milieu grec (p. 82-83). Il n'en allait pas de même chez les chrétiens de langue syriaque, syro-orientaux et "monophysites ». D'après l'A., les Syriens n'auraient en fait pas connu les opinions origénistes d'Évagre ; les Kephalaia Gnostica circulaient par exemple sous une version expurgée de toutes traces suspectes. C'est ainsi que, grâce aux versions syriaques, certains traités, disparus en grec, ont été connus. Pour toute la tradition syro-orientale, Évagre avec Théodore de Mopsueste furent «les deux piliers de l'orthodoxie »: le premier pour la doctrine ascétique, le second pour la théologie et l'exégèse (p. 88). On ne peut qu'être frappé par l'influence profonde qu'exerça Évagre, en particulier sur la spiritualité monastique et mystique chrétienne; la forme littéraire des "chapitres » ou Kẹó $\lambda \alpha_{1} \alpha$ réunis en «centuries» devait faire fortune dans la tradition byzantine comme chez les syroorientaux notamment Isaac de Ninive (p. 92-95). 
5 La seconde partie de ce volume est consacrée à l'œuvre proprement dite. Dans les trois premiers chapitres, l'A. procède à un inventaire commenté ; vient ensuite une section sur les enseignements d'Évagre restitués par ses disciples, écho vraisemblable des leçons orales du maître. A. G. ajoute à cet ensemble les attributions douteuses ou fausses dans les différents corpus linguistiques (grec, syriaque, arménien, copte, arabe, mais aussi chez les auteurs modernes depuis le XVI ${ }^{\mathrm{e}}$.). Suit enfin un chapitre intitulé «Évagre écrivain " particulièrement bienvenu qui fournit nombre d'indications sur les conditions dans lesquelles cette œuvre assez considérable fut élaborée - notamment les ouvrages dont le moine pouvait disposer dans sa cellule.

6 La troisième partie, de loin la plus importante, s'attache en 6 chapitres à l'enseignement d'Évagre. A. G. souligne combien l'état monastique est pour Évagre un préalable pour celui qui désire suivre cette doctrine ascétique et mystique (p. 177) ; le moine doit s'engager à vivre l'hésychia, la chasteté, la simplicité et la pauvreté, le renoncement, à développer les activités spirituelles essentielles à son état: jeûnes, veilles, réflexions sur la vanité du monde, prière sous toutes ses formes (psalmodie, lecture des Écritures, méditations), mais doit aussi travailler pour lutter contre l'acédie, cette terrible tentation de l'abandon (voir en particulier les Bases de la vie monastique ou le traité À Euloge). Pour Évagre, le pratikos est avant tout un hésychaste vivant la semi-anachorèse. Cette ascèse exige un effort constant sur soi-même et ses pensées "méthode spirituelle qui purifie la partie passionnée de l'âme» écrit le Pontique (p. 208, n. 5). Le moine n'est cependant pas un isolé : il peut parfois quitter sa cellule pour visiter des frères malades, demander conseil aux Aînés, et, inversément, a le devoir d'hospitalité.

7 Conformément à la pensée stoïcienne qui les considère comme des maladies de l'âme, Évagre range les passions sous huit rubriques, catégorisation qui, dans l'histoire de la théologie morale, est à l'origine de la liste des sept péchés capitaux : grâce à Jean Damascène, elle passa dans la tradition byzantine et par Cassien puis Grégoire le Grand, dans la tradition latine (p. 212-220). L'A. consacre ensuite une section à la «méthode antirrhétique » d'Évagre : par la science, enjeu mais aussi instrument du combat, le moine peut vaincre les démons. A. G. souligne bien le caractère intellectuel de son ascèse (p. 246): les paroles de l'Écriture constituent la meilleure arme contre les mauvaises pensées et les forces démoniaques qui les inspirent. Cette méthode devait être remise en cause par la suite (cf. p.250-253) par certains maitres spirituels comme Barsanuphe de Gaza ou Jean Climaque - ce qui expliquerait aussi, en partie, la disparition complète du texte grec de l'Antirrhétique.

8 Les chapitres suivants offrent progressivement une réflexion sur les étapes de la vie spirituelle : la vie "pratique » doit conduire, par degrés successifs, vers l'impassibilité (' $\alpha \pi \alpha ́ \theta \varepsilon l \alpha)$, état paisible de l'âme qui a renoncé aux désirs du monde, «fleur de la pratique »; cet état engendre la charité, porte de la science (science des natures créées, puis science de Dieu), « vie gnostique » qui mène à la béatitude (cf. p. 279). Dans ce IV ${ }^{\mathrm{e}}$ chapitre, l'A. développe la pensée d'Évagre en suivant les degrés que comporte l'acquisition de cette science spirituelle : contemplation des choses créées, corporelles

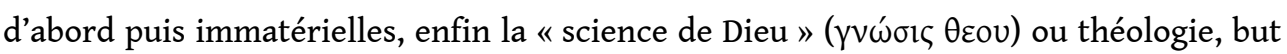
ultime de la vie spirituelle, acquise par purifications successives et grâce à l'impassibilité (p. 284-294).

9 Dans une sous-section intitulée "la mystique évagrienne ", A. G. tente de cerner l'expérience mystique d'Évagre, ces fugitifs instants de «pure prière » : libéré de toute 
distraction, de tout souci des choses terrestres, l'intellect peut alors exercer l'activité qui lui est propre et rejoint ce qu'Évagre appelle le «lieu de Dieu », la lumière sans forme. Cet état n'est jamais définitivement acquis, et l'intellect doit toujours exercer son activité pour y accéder. On le voit, pour Évagre la prière est d'abord intellectuelle : " conversation de l'intellect (vouৎ) avec Dieu ", écrit-il (Prière, 3, cit. p. 298). « La prière sans distraction est la plus haute intellection, activité intellectuelle, de l'intellect " (Prière, 34a, cit. p. 299). Le moine qui est parvenu à cette science divine a ensuite un devoir d'enseigner ses frères - souci pédagogique qui s'inscrit dans une longue tradition catéchétique (p. 323). Cet enseignement est basé sur l'exégèse de l'Écriture (la LXX pour l'AT). Évagre interprète le texte selon sa propre doctrine, distinguant différents sens spirituels selon qu'ils concernent la pratique, la contemplation naturelle ou la théologie, mais toujours avec la volonté de ne dire que ce que chacun peut comprendre - prudence particulièrement perceptible dans le recours fréquent du moine aux formules énigmatiques et obscures (cf. A. G., Keph. gnost., p. 31-37). Cette transmission du savoir, tout en faisant grandir en lui la charité, conduira le frère à développer les vertus de douceur - Évagre y insiste beaucoup - et à se garder de la vaine gloire et de l'orgueil qui peuvent le faire déchoir. Évagre met enfin en garde contre la «science fausse ", l'hérésie (et notamment le docétisme) : « Notre Seigneur a été engendré sans péché, il a mangé véritablement, a été crucifié véritablement; ce n'est pas comme un fantôme qu'il est apparu aux hommes " (Sentences à une vierge 54, cit. p. 331). Depuis la découverte des écrits de Nag-Hammadi, on sait que la présence de sectaires gnostiques est bien attestée en Égypte au $\mathrm{IV}^{\mathrm{e}} \mathrm{s}$. (notamment à Alexandrie, voir M. Tardieu, «Épiphane contre les gnostiques », Tel quel 88, 1981, p. 64-91). Celui qu'il appelle le "gnostique ", c'est-à-dire le moine parvenu à la science divine, a donc à lutter tout spécialement contre les propagateurs de la fausse gnose, contre les hérétiques (p. 331-332).

Le dernier chapitre de l'ouvrage a trait à la métaphysique évagrienne (chap. VI), théologie et sotériologie. Évagre distingue une première création, de purs intellects tendant à la science de Dieu, et une seconde que Dieu aurait faite suite à la «chute » de l'intellect par ce qu'Évagre appelle le mouvement de la liberté - déchéance qui l'éloigna de la connaissance divine ; pour le sortir de cet état, Dieu aurait alors créé les corps, les réalités matérielles, pour redonner à l'intellect la possibilité, par la contemplation des êtres créés, d'accéder à la science de son premier état. A. G. souligne que cette théorie d'une double création est antérieure à Évagre; on la retrouve chez Philon et surtout chez Origène, mais aussi chez saint Basile (p. 346-347).

11 Évagre reste sévère contre les faux gnostiques ou les manichéens qui, méprisant leur corps, «blasphèment contre leur Créateur » en refusant d'accepter ce don qu'il leur a fait (p. 349). Sa théologie est fidèle à celle de son maître Grégoire (p. 338-342) : Dieu,

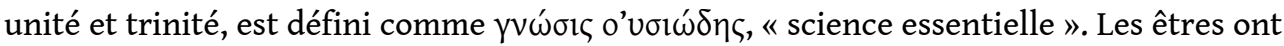
été créés à seule fin de Le connaître. Au niveau sotériologique (chap. VII), Évagre situe le monde des hommes entre celui des anges et celui des démons : mais il n'y a pas de différence de nature entre ces êtres, et le passage d'un état à l'autre est possible, vers le meilleur ou le pire (p. 361-362). Grâce à la Providence, toutes les natures déchues parviendront à l'état angélique, à la connaissance divine, à la béatitude, avec, comme médiateur de salut, le Christ, sur qui repose par excellence la science de l'unité. Sur le plan eschatologique (chap. X, p. 396-404), l'influence d'Origène et de Grégoire de 
Nazianze sur Évagre apparait probable lorsqu'il décrit le retour des êtres raisonnables à leur condition première.

12 Par cet ouvrage, qui fait désormais référence, fruit des travaux de toute une vie, A. G. apporte ainsi une contribution fondamentale et remarquable à l'histoire de la spiritualité chrétienne orientale et occidentale.

\section{AUTEURS}

\section{FLORENCE JULLIEN}

EPHE (Sciences religieuses), Paris 